\section{P67 IMPLEMENTING BTS ASTHMA DISCHARGE BUNDLE IMPROVES DISCHARGE PLANNING IN CHILDREN}

${ }^{1} \mathrm{NT}$ Patel, ${ }^{2} \mathrm{~V}$ Moreton, ${ }^{2} \mathrm{~L}$ Nair, ${ }^{2} \mathrm{E}$ Eckersall, ${ }^{2} \mathrm{JC}$ Furness. ${ }^{1}$ Medical School, University of Newcastle upon Tyne, Newcastle upon Tyne, UK; ${ }^{2}$ County Durham and Darlington NHS Foundation Trust, Darlington, UK

\subsection{6/thoraxjnl-2017-210983.209}

Introduction The Challenge The 2015 BTS Paediatric Asthma Audit had showed unit's performance at delivering a Written Management Plan (WMP) at discharge to have deteriorated to $2 \%$. The same audit found a national average of $50 \%$. We were concerned about how to improve this. In 2016 the BTS introduced the Asthma Care Bundle.

Method We asked staff why they did not always use the bundle. We designed A4 posters, an A4 mouse mat, group training delivered by nursing staff, real time private one to one feedback to nurses and doctors who forgot to use the bundle, group teaching by a nurse (VM), regular reminders by a consultant of the audit (JF) and an audit by a medical student (NP). A department Asthma Care Pathway was updated (LN) to encourage staff to use the discharge bundle. NP and did a retrospective case note audit of admissions between 1/9/16 to 20/1/2017 comparing the number of children discharged with a new and previous WMP who had an asthma care pathway (ACP), diagnosis of asthma, on inhaled corticosteroids (ICS) and those between $2-5$ years and over 5 years of age.

Results

\begin{tabular}{|c|c|c|c|c|c|}
\hline \multicolumn{6}{|c|}{ Patients with WMP } \\
\hline & ICS & Diagnosis & $\mathrm{ACP}$ & New & Previous \\
\hline & & Asthma & & WMP & WMP \\
\hline $2-5$ & 22 & 17 & 16 & 13 & 5 \\
\hline Over & 23 & 31 & 20 & 17 & 7 \\
\hline \multicolumn{6}{|l|}{$5 \mathrm{~s}$} \\
\hline
\end{tabular}

The use of WMP at discharge rose to 50\% for children diagnosed with asthma and $80 \%$ for those using an Asthma Care Pathway including the BTS Asthma Care Bundle.

Conclusions and Implications Implementing the BTS discharge bundle in paediatrics is hard work. The neglect of this hard work is associated with a decrease in WMP use. Multiple tools and clear guidelines were effective at improving use by staff. Most important appears to be the use an ACP.

\section{P68 ASTHMA SYMPTOM IMPROVEMENTS WITH BENRALIZUMAB ARE ASSOCIATED WITH IMPROVEMENTS IN ACTIVITY FUNCTIONS AND QUALITY OF LIFE FOR PATIENTS WITH SEVERE, UNCONTROLLED ASTHMA: RESULTS OF POOLED PHASE III BENRALIZUMAB STUDIES}

G Gopalan, XXu, S O'Quinn, I Hirsch. AstraZeneca, Gaithersburg, MD, US

10.1136/thoraxjnl-2017-210983.210

Introduction and Objectives Benralizumab is an anti-eosinophilic monoclonal antibody that improves daily symptoms for patients with severe, uncontrolled asthma with eosinophilic inflammation. This study evaluated the association of asthma symptom improvements with activity function and healthrelated quality of life assessments.

Methods Pooled analyses of two Phase III benralizumab trials (NCT01928771, NCT01914757) of adult patients with severe asthma (1474 benralizumab, 742 placebo) who received highdosage inhaled corticosteroids/long-acting $\beta_{2}$-agonists were conducted. Daily asthma symptoms (daytime and night-time symptoms), daily activity function (activity limitations, activity avoidance, need to pace oneself during activities), feeling stress, feeling tired, rescue medication use, night-time awakenings, Asthma Control Questionnaire, 6-question version (ACQ6), and Standardised Asthma Quality of Life Questionnaire for patients 12 years and older (AQLQ[S]+12) were captured with an electronic diary. Daily assessments were summarised as biweekly means. Spearman's rank correlation coefficient was used to examine the association of daily asthma symptoms with other aforementioned diary items and with forced expiratory volume in $1 \mathrm{~s}\left(\mathrm{FEV}_{1}\right)$. Associations of $<0.2,0.2-$ $<0.4, \quad 0.4-<0.6,0.6-<0.8$, and $0.8-1.0$ were considered "very weak," "weak," "moderate," "strong," and "very strong," respectively.

Abstract P68 Table 1 Spearman's Rho correlation between asthma-related symptoms and other patient-reported outcomes and $\mathrm{FEV}_{1}$ at baseline and end of treatment

\begin{tabular}{|c|c|c|c|c|}
\hline \multirow[t]{2}{*}{ Variables For Correlation } & \multicolumn{2}{|l|}{ Baseline } & \multicolumn{2}{|c|}{$\begin{array}{l}\text { Change From Baseline } \\
\text { to End of Treatment }\end{array}$} \\
\hline & Benralizumab & Placebo & Benralizumab & Placebo \\
\hline \multicolumn{5}{|l|}{ Daily diary assessments } \\
\hline $\begin{array}{l}\text { Activity function: Limitation of } \\
\text { activities }\end{array}$ & 0.77 & 0.76 & 0.73 & 0.66 \\
\hline $\begin{array}{l}\text { Activity function: Avoidance of } \\
\text { activities }\end{array}$ & 0.76 & 0.73 & 0.72 & 0.67 \\
\hline $\begin{array}{l}\text { Activity function: Need to pace } \\
\text { self }\end{array}$ & 0.76 & 0.72 & 0.71 & 0.66 \\
\hline Feeling tired & 0.76 & 0.72 & 0.70 & 0.66 \\
\hline Feeling stressed & 0.50 & 0.48 & 0.49 & 0.36 \\
\hline $\begin{array}{l}\text { Percentage of night-time } \\
\text { awakening }\end{array}$ & 0.65 & 0.62 & 0.48 & 0.45 \\
\hline $\begin{array}{l}\text { Total rescue medication use } \\
\text { (puffs per day) }\end{array}$ & 0.57 & 0.56 & 0.51 & 0.49 \\
\hline ACQ-6 score & 0.68 & 0.68 & 0.64 & 0.58 \\
\hline \multicolumn{5}{|l|}{$\mathrm{AQLQ}(\mathrm{S})+12$} \\
\hline Overall & -0.60 & -0.55 & -0.61 & -0.52 \\
\hline Symptoms & -0.62 & -0.59 & -0.61 & -0.53 \\
\hline Activity limitation & -0.54 & -0.50 & -0.55 & -0.48 \\
\hline Emotional function & -0.47 & -0.44 & -0.54 & -0.41 \\
\hline Environmental stimulation & -0.37 & -0.33 & -0.42 & -0.35 \\
\hline Pre-bronchodilator $\mathrm{FEV}_{1}(\mathrm{~L})$ & -0.09 & -0.08 & -0.21 & -0.13 \\
\hline
\end{tabular}

ACQ-6, Asthma Control Questionnaire, 6-question version; $A Q L Q(S)+12$, Standardised Asthma Quality of Life Questionnaire for patients 12 years and older; FEV $_{1}$, forced expiratory volume in $1 \mathrm{~s}$. All $\mathrm{p}<0.05$

Results Associations were observed between asthma symptoms and daily activity function items, daily stress, ACQ-6, AQLQ (S) +12 overall and domain scores, and $\mathrm{FEV}_{1}$ at baseline and change from baseline to end of treatment in both benralizumab and placebo arms (table). Strong correlations were 